УДК $582.24(477)$

Кочергіна A.B. https://orcid.org/0000-0003-3998-7028, Scopus ID 54079866200

\title{
ПЕРШІ ЗНАХІДКИ МІКСОМІЕТІВ НА ТЕРИТОРІЇ СЕЙМСЬКОГО РЕГІОНАЛЬНОГО ЛАНДШАФТНОГО ПАРКУ
}

\author{
(C) Кочергіна А.В. \\ Харківський національний педагогічний університет імені Г.С. Сковороди \\ stacyscreations86@gmail.com \\ https://doi.org/10.34142/2708-5848.2020.22.2.03
}

У результаті польового дослідження, проведеного у серпні 2019 р., на території Сеймського регіонального ландшафтного парку виявлено 25 видів міксоміцетів, що відносяться до 17 родів, 7 родин, 6 порядків та 2 підкласів класу Myхоmycetes. Згідно з оцінкою за скорегованим критерієм Chao1, виявлений перелік складає 77.6\% видового складу біоти. Індекс різноманіття Маргалєфа для дослідженої біоти склав 13.7, індекс Шеннона - 1.32, індекс Сімпсона - 0.06, а індекс Пілоу - 0.28. Усі виявлені види $є$ новими для української частини Середньоруських лісів. Один з виявлених видів, Comatricha anomala, є новим для України. Цей вид знайдено на мертвій деревині Betula pendula. Серед субстратних груп міксоміцетів у Сеймському РЛП переважають ксилофіли (18 видів, 65.4 \%) та кортикофіли (8; 31\%). Arcyria cinerea (Bull.) Pers. та Stemonitis pallida Wing, продемонстрували мішану екологічну стратегію. Серед субстратоутворючих рослин найбільше різноманіття міксоміцетів спостерігалося на субстратах, утворених відносно нечисленними видами: P. tremula (13 видів, $50.0 \%), Q$. robur $(11 ; 42.3 \%)$ та $B$. pendula (8 видів; 30.8\%), у той час як на панівному у дослідженій частині парку P. sylvestris було виявлено лише 6 видів міксоміцетів $(23,1 \%)$. Серед порядків за кількістю видів переважають Stemonitidales (11 видів; 42.3\%) та Trichiales (8 видів; 30.8\%), серед родин - Amaurochaetaceae $(6 ; 23,1 \%)$ та Trichiaceae (8; 30.8\%), серед родів - Arcyria (4; 15,4\%), Lycogala, Stemonitis, Stemonitopsis та Comatricha (по 2 види; 7,7\%). На субстратах, утворених різними видами рослин, таксономічна структура біоти міксоміцетів суттєво різниться. За співвідношенням між видами Trichiales та Stemonitidales субстратоутворюючі рослини утворюють такий ряд: P. sylvestris, B.pendula, P.tremula, R. pseudoacacia та $Q$. robur утворюють ряд $3.0 \rightarrow 1.5 \rightarrow 1.5$ $\rightarrow 0.5 \rightarrow 0.25$.

Ключові слова: Eитусетоzоа, біорізноманіття, екологічні групи, Середньоруські ліси, таксономічна структура.

Сеймський регіональний ландшафтний парк (подалі СРЛП) - найбільша за площею природно-заповідна територія Сумської області $(98857,9$ га), що знаходиться в центральній частині регіону, простягнувшись зі сходу на захід уздовж долини ріки Сейм.

Територія парку охоплює частини чотирьох адміністративних районів. Східна, найбільша ділянка, знаходиться в Путивльському районі (36210,6 га), де в територію парку входить межиріччя СеймКлевень; далі на захід розташовані ділянки, що належать до Конотопського (30865,4 га), Кролевецького (24664,6 га) та Буринського (7117,3 га) районів. До складу парку входить заплава Сейму i перша надзаплавна тераса, краще виражена на лівому березі річки. Складається вона в основному з піщаних і супіщаних річкових відкладень. Менші площі займають друга і третя надзаплавні тераси, репрезентовані в східній частині парку. Ці тераси складені здебільшого суглинковими породами [10].
Згідно 3 ботаніко-географічним районуванням України, територія СРЛП належить до Середньоруської підпровінції Східноєвропейської провінції Європейської широколистянолісової області [4]. Відповідно до прийнятого у вітчизняній мікології районування, територія пару знаходиться у межах Середньоруських лісів [3].

Лісова рослинність на території СРЛП представлена борами, сосново-дубовими суборами, чисто дубовими, липоводубовими та кленово-липово-дубовими лісами. До основних лісоутворюючих порід на території СРЛП належать Pinus sylvestris L., Quercus robur L., Populus tremula L., Betula pendula L., у другому ярусі трапляються Ulmus laevis Pall., Acer camestre L., в заплавах - Salix spp., Populus spp., в чагарниковому ярусі трапляються Coryllus avalana (L.) H.Karst., Amorpha fruticosa L., Sambucus nigra L., S. Racemosa L. [10]. 
3 моменту заснування парка (1995р.), видовий склад та екологічні особливості міксоміцетів тут ніколи не ставали об'єктом самостійного дослідження. Однак відомо, що біоти міксоміцетів природних резерватів, які мають близькі до СРЛП

\section{МАТЕРІАЛИ І МЕТОДИ}

Дослідження міксоміцетів СРЛП були проведені нами 19-22 серпня 2019 р. Збори проводились уздовж таких маршрутів:

1) 19.08.2019: урочище Боромля, $51.39332^{\circ}$ пн. ш., $33.56060^{\circ}$ сх. д., 129 м н. p. M.

2) 20.08.2019: околиці бази «Лісовий хутір», на південь від 51.37839 ${ }^{\circ}$ пн.. ш., $33.47893^{\circ}$ сх. д., 121 м н. р. м., до $51.37808^{\circ}$ пн. ш., $33.48191^{\circ}$ сх. д., 120 м н. р. м.

3) 22.08.2019: околиці бази «Лісовий хутір», на південь - південний захід від $51.40168^{\circ}$ пн. ш., $33.46171^{\circ}$ сх. д., 120 м н. р. м., до $51.38352^{\circ}$ пн. ш., $33.47624^{\circ}$ сх. д., 146 м н. p. м.

Матеріал збирали за загальноприйнятою методикою, 3 використанням польових зборів та методу вологої камери [2]. Безпосередній збір плодових тіл у польових умовах здійснювали таким чином. В ході пересування пішохідним маршрутом оглядали субстрати, на яких трапляються міксоміцети: стовбури дерев, колоди, пні, корчі, гілковий та листяний опад. Для огляду субстратів у важкодоступних затінених місцях використовувався ліхтарик. В разі виявленні зрілих

\section{РЕЗУЛЬТАТИ}

У результаті проведеного дослідження на території СРЛП було виявлено 25 видів міксоміцетів, що, згідно з системою Леонтьєва зі співавт. [7], відносяться до 17 родів, 7 родин, 6 порядків та 2 підкласів площу та різноманіття рослинного покриву, нараховують принаймні 120-160 видів [9], тому дослідження видового складу цих організмів на вказаній території $€$ цілком доцільними.

плодових тіл міксоміцетів, їх за допомогою ножа або секатора відокремлювали від субстрату разом з фрагментом останнього і переносили в закриті картонні коробки. У лабораторії зібраний матеріал відкривали і поміщали в теплі сухі умови до повного висихання субстратів.

Метод вологої камери полягає в інкубації зразків субстратів у чашках Петрі на зволоженому фільтрувальному папері. Це сприяє проростанню спор міксоміцетів, що зберігаються у субстраті, і подальшому розвиту їхніх плодових тіл. В нашому дослідженні до вологих камер були досліджені зразки кори живих дерев (11 рослин). Було закладено 30 вологих камер. Інспектування камер здійснювалося на 6-7, 10-13 та 18-20 дні від початку експерименту.

Ідентифікацію видів здійснювали 3 використанням визначника М. Пуляна зі співавт. [8]. Матеріал дослідження зберігається у мікологічній секції Наукового гербарію Харківського національного педагогічного університету ім. Г.С. Сковороди (CWP).

класу Myхоmycetes. Також був виявлений один представник класу Ceratiomyхоmycetes - Ceratiomyxa fruticulosa, що $\epsilon$ традиційним об'єктом міксоміцетології (Табл. 1).

Таблиия 1

Систематичний список міксоміцетів Сеймського РЛП

\begin{tabular}{|l|l|l|}
\hline $\begin{array}{l}\text { № } \\
\text { з/п }\end{array}$ & Вид & Субстрат \\
\hline КЛАС СЕRАTIOMYXOMYCETES D. Hawksw., B. Sutton \& Ainsw. \\
\hline $1 . \quad$ Ceratiomyxa fruticulosa (O.F. Müll.) T. Macbr. & w+BP \\
\hline \multicolumn{2}{|l|}{ КЛАС MYXOMYCETES G. Winter } \\
\hline \multicolumn{2}{|l}{ ПІДЛАC LUCISPOROMYCETIDAE } \\
Leontyev, Schnittler, S.L. Stephenson, Novozhilov \& Shchepin \\
\hline
\end{tabular}


RETICULARIALES Leontyev, Schnittler, S.L. Stephenson, Novozhilov \& Shchepin

Reticulariaceae Chevall.

2. Lycogala epidendrum (L.) Fr.

$\mathrm{w}+\mathrm{PT}$

3. L. exiguum Morgan

$\mathrm{w}+\mathrm{PT}$

LICEALES E. Jahn

Liceaceae Chevall.

4. $\quad$ Licea kleistobolus G.W. Martin

$b^{*} \mathrm{PS}, \mathrm{b} * \mathrm{RP}$

TRICHIALES T. Macbr.

Trichiaceae Chevall.

5. Arcyria cinerea (Bull.) Pers

6. A. incarnata (Pers. ex J.F. Gmel.) Pers.

7. A. obvellata (Oeder) Onsberg

8. A. pomiformis (Leers) Rostaf.

9. Hemitrichia clavata (Pers.) Rostaf.

$\mathrm{w}+\mathrm{PT}, \mathrm{b} * \mathrm{RP}$

$\mathrm{w}+\mathrm{BP}$

$\mathrm{w}+\mathrm{UL}, \mathrm{w}+\mathrm{QR}$

$b^{*} \mathrm{PD}, \mathrm{b}^{*} \mathrm{QR}$

$\mathrm{w}+\mathrm{PT}$

10. Metatrichia vesparia (Batsch) Nann.-Bremek. ex G.W. Martin \& Alexop.

$\mathrm{w}+\mathrm{BP}, \mathrm{w}+\mathrm{PT}, \mathrm{w}+\mathrm{QR}, \mathrm{b}+\mathrm{BP}$

11. Perichaena chrysosperma (Curr.) Lister $b^{*} P S, b^{*} U L, b^{*} Q R, b^{*} R P$

12. Trichia varia (Pers. ex J.F. Gmel.) Pers. $\mathrm{w}+\mathrm{PT}$

ПІДКЛАС СОLUМЕLLOMУСЕТIDAE Leontyev, Schnittler, S.L. Stephenson, Novozhilov \& Shchepin

ECHINOSTELIALES G.W. Martin

Echinosteliaceae Rostaf. ex Cooke

13. Echinostelium minutum de Bary

$\mathrm{b} * \mathrm{BP}, \mathrm{b} * \mathrm{PS}, \mathrm{b} * \mathrm{QR}$

STEMONITIDALES T. Macbr.

Stemonitidaceae Fr.

14. Macbrideola cornea (G. Lister \& Cran) Alexop.

15. Stemonitis flavogenita E. Jahn

16. S. pallida Wing.

17. S. smithii T. Macbr.

18. Symphytocarpus flaccidus (Lister) Ing \& Nann.-Bremek.

\begin{tabular}{l|l}
\hline b*PS, b*QR, b* RP \\
w+PT, w+QR \\
w+PT, b*PD \\
w+BP, w+PT, w+QR \\
w+PT
\end{tabular}

Amaurochaetaceae Rostaf. ex Cooke

19. * Comatricha anomala Rammeloo

20. C. ellae Härk.

21. Enerthenema papillatum (Pers.) Rostaf.

22. Paradiacheopsis fimbriata (G. Lister \& Cran) Hertel

23. Stemonitopsis hyperopta (Meyl.) Nann.-Bremek.

24. S. typhina (F.H. Wigg.) Nann.-Bremek.

$\mathrm{w}+\mathrm{BP}$

$\mathrm{b} * \mathrm{QR}$

$\mathrm{b}^{*} \mathrm{PS}, \mathrm{b} * \mathrm{QR}$

$\mathrm{b} * \mathrm{PS}$

$\mathrm{w}+\mathrm{PT}$

$\mathrm{w}+\mathrm{PT}, \mathrm{w}+\mathrm{BP}$

Physarales T. Macbr.

Physaraceae Chevall.

$25 . \quad$ Fuligo septica (L.) F.H. Wigg.

26. Physarum globuliferum DC.

$\mathrm{w}+\mathrm{PT}, \mathrm{b}+\mathrm{QR}$

$\mathrm{w}+\mathrm{BP}$

П р и м і т к и : Типи субстратів: $\mathrm{b}^{*}$ - кора живого дерева, $\mathrm{b}+$ - кора відмерлого дерева; $\mathrm{w}^{+}-$мертва деревина. Субстратоутворюючі рослини: ВP - Betula pendula, PT - Populus tremula, PD - Prunus domesticus, RP - Robinia pseudoacacia,

$\mathrm{PS}$ - Pinus sylvestris, $\mathrm{QR}$ - Quercus robur, $\mathrm{UL}$ - Ulmus laevis.

Оцінка повноти проведеного нами дослідження біоти здійснювалася двома способами: з використанням скорегованого коефіцієнту Chao1 [1] для усієї зібраної 
колекції та окремо для матеріалів, зібраних методом вологої камери. В першому випадку обраний критерій показав, що очікувана кількість видів міксоміцетів у СРЛП сягає 33.5, тобто нами наразі виявлено 77.6\% наявного видового складу. Очікувана кількість видів, що виявляються у вологих камерах, сягнула 10.3, що відповідає 97.1\% виявлених нами видів.

Індекс різноманіття Маргалєфа для дослідженої біоти склав 13.7, індекс Шеннона -1.32 , індекс Сімпсона -0.06 , а індекс Пілоу - 0.28. Вказані значення свідчать про помірний рівень видового багатства та високий рівень вирівненості видового спектру досліджуваної біоти [5].

Усі виявлені види є новими для української частини Середньоруських лісів. Один 3 виявлених видів, Comatricha anomala, є новим для України. Нижче наводимо опис цієї знахідки.

Comatricha anomala Rammeloo, Bull. Jard. bot. Univers. Belgrade 46: 237 (1976), (Puc. 1). Спорокарпи у групах, 1.5-3,0 мм завв. Споротека циліндрична, 0.4-0.5 мм діам., темно-коричнева, закруглена біля основи та верхівки. Ніжка складає менше третини висоти спорокарпа, чорна, блискуча, біля основи розширена, у прохідному світлі червоно-бура. Гіпоталюс плівчастий, жовтувато-червонуватий, слабо радіально складчастий. Колумелла циліндрична, непрозора, доходить до верхівки споротеки. Капіліцій розгалужений під прямими кутами, анастомозований, опорні нитки середньої товщини, темні; периферійні нитки напівпрозорі, з дрібними блідими вільними кінцями, утворюють товсту, але дуже фрагментарну поверхневу сітку. Спори в масі темно-коричневі, у прохідному світлі коричнево-сірі, кулясті, 9-10 мкм діам., бородавчасті, 3 окремими невеликими ділянками сітки.

Знахідка в Україні: Сеймський РЛП, на мертвій деревині Betula pendula, 20.08.2019, 51.38385 ${ }^{\circ}$ пн. ш., $33.48181^{\circ}$ cх. д., 125 м н. р. м., CWP3580, leg. et del. Кочергіна А.В.

Загальне поширення: Свропа: Австрія, Іспанія, Італія, Німеччина, Норвегія, Португалія, Франція; Північна Америка: Куба, Мексика (за даними gbif.org).
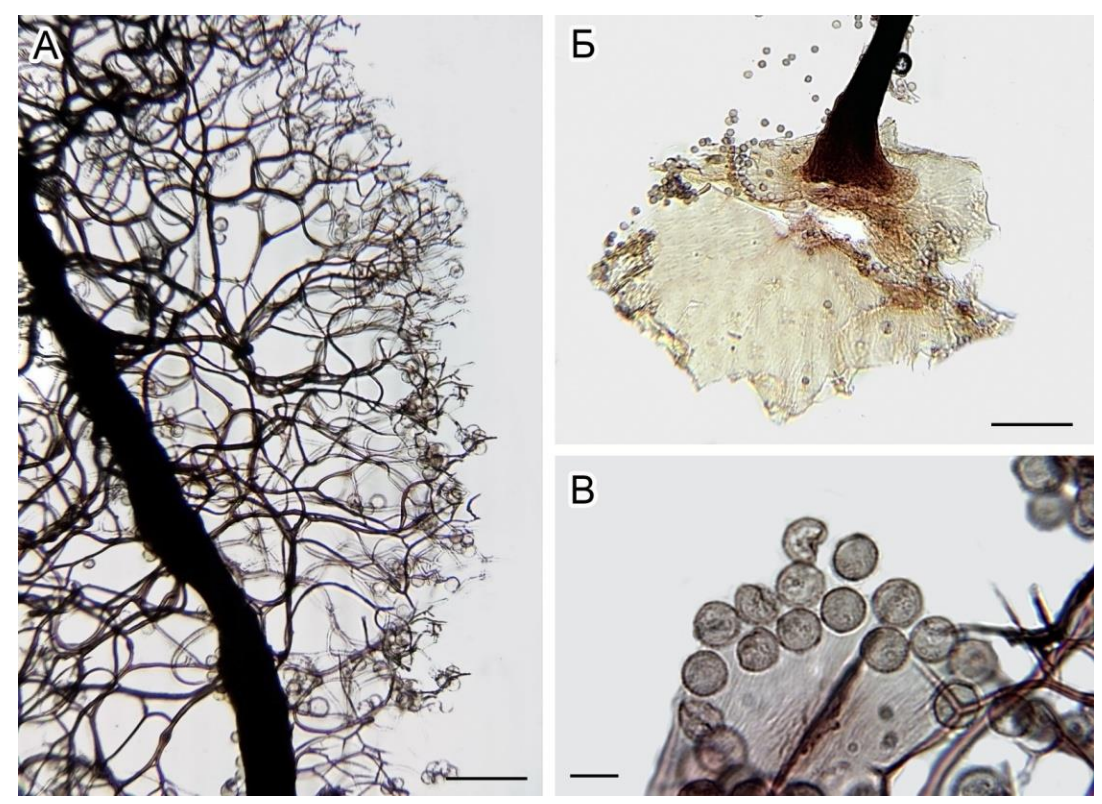

Puc. 1. Comatricha anomala Rammeloo. А - система капіліцію. Б - гіпоталюс. В - спори та елементи капіліцію. Шкали: А, Б - 50 мкм, В - 10 мкм.

\section{ОБГОВОРЕННЯ}

Екологічні групи міксоміцетів виді-ляються, насамперед, за типом та видовою приналежністю субстратоутворюючого організму [6]. За цією ознакою міксоміцети розділяють на ксилофільні, кортикофільні, грунтово-гербофільні, бріофільні, підстилкові та копрофільні. У дослідженому матеріали були виявлені представники 
перших двох груп, розподіл між якими за кількістю видів міксоміцетів виявився типовим для лісів помірної зони: 18 видів ксилофілів (65.4\% від загального видового складу) та 8 видів кортикофілів (31\%). Ще 2 види (11.8\%), a саме Arcyria cinerea (Bull.) Pers. та Stemonitis pallida Wing., продемонстрували мішану екологічну стратегію. Для першого 3 цих видів це $\epsilon$ додатковим свідченням його генетичної гетерогенності [11].

Субстрати, утворені панівними видами дерев, зазвичай представлені найбільшою кількістю видів міксоміцетів [6]. Однак в умовах СРЛП найбільше різноманіття міксоміцетів спостерігалося на субстратах, утворених відносно нечисленною P. tremula (13 видів, 50.0\% від їхньої загальної кількості), та також локально поширеними видами $Q$. robur (11; $42.3 \%$ ) та $B$. pendula (8 видів; $30.8 \%$ ), у той час як на панівному у дослідженій частині парку P. sylvestris було виявлено лише 6 видів міксоміцетів (23,1\%). Варто відзначити, що P. sylvestris в цілому вважається дуже сприятливим для міксоміцетів субстратом [6], тож низьку рясність досліджуваних організмів на цьому субстраті пояснити складно. Певний внесок у різноманіття досліджуваної групи внесли також і нечисленні за кількістю виявлених видів субстратоутворюючі рослини: R. pseudoacacia $(4 ; 15.4 \%)$, U.laevis та P.domestica (по 2; 7.7\%).

В цілому, види, що показали високе різноманіття міксоміцетів, характеризуються м'якою, дуже гігроскопічною деревиною [6], що безперечно сприяє розвитку міксоміцетів на їхній деревині. Цей чинник $\epsilon$ особливо значущим у сухі періоди, тож виявлену особливість субстратної приналежності міксоміцетів СРЛП можна цілком пояснити відносно сухою погодою у період проведення дослідження.

Таксономічна структура дослідженої біоти виявилася звичайною для широколистянолісової зони України. 326 видів, 14 видів відносяться до підкласу Columellomycetidae, a 11 - до підкласу Lucispo- romycetidae. Серед порядків темноспорових міксоміцетів за кількістю видів переважав Stemonitidales (11 видів; 42.3\% від їхньої загальної кількості), сильно поступаються йому Physarales $(2 ; 7.7 \%)$ та Echinosteliales $(1 ; 3.9 \%)$. Серед родин Columellomycetidae найбільшої кількістю видів відзначаються Amaurochaetaceae (6; $23.1 \%$ ), поступаються їм Stemonitidaceae (5; 19.2\%), Physaraceae $(2 ; 7.7 \%)$ та Echinosteliaceae $(1 ; 3,9 \%) .3$ родів темноспорових міксоміцетів найбільшу кількість видів продемонстрували Stemonitis, Stemonitopsis та Comatricha (по 2 види; 7,7\%). Серед порядків світлоспорових міксоміцетів за кількістю видів переважав Trichiales (8 видів; $30.8 \%$ від їхньої загальної кількості), далі слідують Reticulariales $(2 ; 7.7 \%)$ та Liceales $(1 ; 3.9 \%)$. Нарешті, серед родин Lucisporomycetidae провідне положення також займають Trichiaceae $(8 ; 30.8 \%)$, а серед родів Arcyria $(4 ; 15.4 \%)$ та Lycogala $(2 ; 7.7 \%)$, решта родів представлені єдиним видом. Представники п'яти провідних родів утворюють $46.2 \%$ видового складу міксоміцетів СРЛП.

На субстратах, утворених різними видами рослин, таксономічна структура біоти міксоміцетів суттєво різниться (Рис. 2). Так, на корі $P$. sylvestris переважають представники Amaurochaetaceae, на корі та деревині B.pendula широко представлені Amaurochaetaceae та Trichiaceae, на P.tremula та $Q$. robur понад половину таксономічного спектру складають Trichiaceae та Stemonitidaceae. Найбільшу частку таксономічного спектру родина Trichiaceae складає на корі $R$. pseudoacacia.

3 літератури відомо [6], що біоту міксоміцетів на певному субстраті добре характеризує кількісне співвідношення між видами порядків Trichiales та Stemonitidales. У досліджуваному матеріалі ці співвідношення для P. sylvestris, B. pendula, $P$. tremula $R$. pseudoacacia ma $Q$. robur утворюють ряд $3.0 \rightarrow 1.5 \rightarrow 1.5 \rightarrow 0.5 \rightarrow$ 0.25 . 


\section{ПІДСУМОК}

Одержані дані дозволяють охарактеризувати біоту міксоміцетів Сеймського РЛП як ксилофільно-кортикофільну, 3 переважанням Stemonitidales i Trichiales та тяжінням до споруляції на видах лісоутворюючих

рослин, що характеризуються м'якою деревиною. Найвідмінніші типи таксономічного спектру міксоміцетів формуються на субстратах, утворених $P$. sylvestris (переважання Stemonitidales) та $Q$. robur (переважання Trichiales).

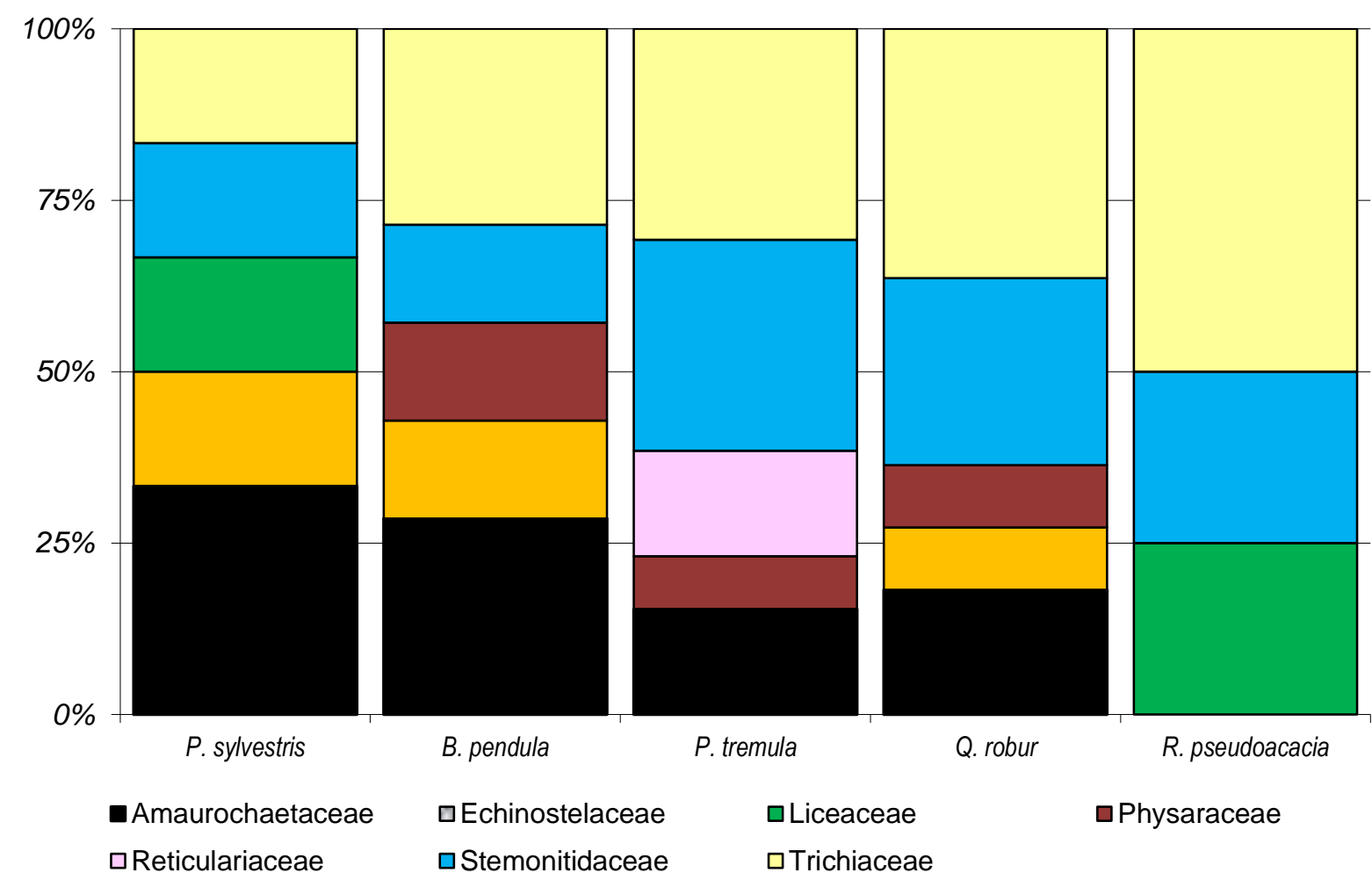

Puc. 2. Таксономічний спектр світлоспорових міксоміцетів на деяких видах субстратоутворюючих рослин.

\section{תimepamypa}

1. Chao A., Hsieh T.C., Chazdon R.L., Colwell R.K., Gotelli N.J. (2015) Unveiling the species-rank abundance distribution by generalizing the GoodTuring sample coverage theory. Ecology 96(5): 1189-1201. doi.org/10.1890/14-0550.1.

2. Goad A.E., Stephenson S.L. (2013) Myxomycetes appearing in moist chamber cultures on four different types of dead leaves. Mycosphere 4 (4): 707-712. Doi 10.5943/mycosphere/4/4/7.

3. Heluta V.P. (1989) Fungal Flora of Ukraine. Downy Mildew Fungi. Kyiv: Naukova dumka.

4. Geobotanical zoning of Ukrainian S. S. Republic (1977). Kyiv: Naukova dumka.

5. Leontyev D.V. (2007) Biodiversity analysis in mycology: a textbook. Kharkiv: Osnova.

6. Leontyev D.V. (2007) Phytocenotic connections of Myxomycetes (Myxomycota) in Gomol'shanskie Lesa National Park, Ukraine. Russ. J. Ecol. 38(3): 214-216.
7. Leontyev D.V., Schnittler M., Stephenson S., Novozhilov Y.K., Shchepin O.V. (2019) Towards a phylogenetic classification of Myxomycetes. Phytotaxa 399(3): 209-238. https://doi.org/10.11646/phytotaxa.399.3.5.

8. Poulain M., Meyer M., Bozonnet J. (2011) Les Myxomycètes. Dauphiné-Savoie: Sarl Editions.

9. Prylutskyi O.V., Akulov O.Yu., Leontyev D.V., Ordynets O.V., Yatsiuk I.I., Usichenko A.S., Savchenko A.O. (2017) Fungi and Fungus-like Organisms of Homilsha Forests National Park, Ukraine. Mycotaxon 132(3): 1-56.

10. Reserve treasures of the Sumshchina (2001) / Ed. T.L. Andriyenko. Sumy: Djerelo.

11. Walker L.M., Leontyev D.V., Stephenson S.L. (2015) Perichaena longipes, a new myxomycete from the Neotropics. Mycologia 107 (5): 10121022. 
UDC $582.24(477)$

\title{
THE FIRST FINDINGS OF MYXOMYCETES ON THE TERRITORY OF THE SEYMSKYI REGIONAL LANDSCAPE PARK (UKRAINE)
}

\author{
Kochergina A.V.
}

As a result of a field study, carried out in August 2019, 25 species of myxomycetes from 17 genera, 7 families, 6 orders and 2 subclasses of the class Myxomycetes were collected in the area of the Seymskyi Regional Landscape Park (Sumy region, Ukraine). According to the bias-corrected Chao1 estimator, the collection represents $77.6 \%$ of the myxomycetes species composition of the park. The biodiversity indexes of the studied biota are as follows: Margalef's diversity index -13.7 , Shannon's index -1.32 , Simpson's index -0.06 , Pielou's index -0.28 . All identified species are new to the Ukrainian part of the Central Russian Upland forests. One of them, Comatricha anomala, found on the dead wood of Betula pendula, is new to Ukraine. Among the substrate groups of myxomycetes, xylophilic (18 species, $65.4 \%)$ and corticolous $(8 ; 31 \%)$ species dominate in the park. Arcyria cinerea and Stemonitis pallida demonstrate a mixed substrate strategy. Among the substrate-forming plants, the greatest diversity of myxomycetes was observed on substrates, formed by relatively unabundant plant species: Populus tremula (13 myxomycete species, 50.0\%), Quercus robur (11; 42.3\%) and Bbetula pendula (8 species; $30.8 \%$ ), while only 6 species of myxomycetes $(23.1 \%$ ) were found on the dominant plant species of $P$. sylvestris. Among the orders of myxomycetes, by number of species, Stemonitidales (11 species; $42.3 \%)$ and Trichiales ( 8 species; 30.8\%) prevail in the park, among the families the most abundant were Amaurochaetaceae (6; $23.1 \%$ ) and Trichiaceae $(8 ; 30.8 \%)$, among the genera they are Arcyria (4; 15.4\%), Lycogala, Stemonitis, Stemonitopsis and Comatricha (2 species each; 7.7\%). The taxonomic structure of myxomycete biota differs significantly on the substrates, formed by different plant species. According to the ratio between species Trichiales and Stemonitidales, the substrate-forming plants form the following row: P. sylvestris, B.pendula, P.tremula, $R$. pseudoacacia and $Q$. robur (3.0 $\rightarrow 1.5 \rightarrow 1.5 \rightarrow 0.5 \rightarrow 0.25$ correspondingly).

Key words: Eumycetozoa, biodiversity, ecological groups, Middle-Russian Forests, taxonomic structure.

Стаття надійшла 15. 09. 2020 р. Рекомендована до друку на засіданні редакційної колегї після рецензування 